\title{
Recursivity by Organizational Design: The Case of the Forest Stewardship Council
}

Article by an MPIfG researcher

Olga Malets: Recursivity by Organizational Design: The Case of the Forest Stewardship Council. In: Global Policy 8(3), 343-352 (2017). Wiley-Blackwell

The original publication is available at the publisher's web site: https://doi.org/10.1111/1758-5899.12413
Olga Malets

University of Freiburg

\section{Abstract}

This article examines recursive processes in the Forest Stewardship Council (FSC), a nonstate forest standard-setting and accreditation organization. The FSC has developed numerous organizational structures and procedures that help it pool and analyze stakeholder input and feedback in standard-setting and implementation. We conceptualize recursive processes of stakeholder input and feedback and organizational responsiveness as recursivity by design. The article focuses on organizational legitimacy as a driver of recursive processes. The FSC's extensive participation procedures and structures present opportunities for incorporating stakeholder input and feedback in standard-setting and make it a responsive, legitimate, and effective governance scheme. It also enables the FSC to deal with challenges to its legitimacy and effectiveness. Whereas challenges associated with stakeholder participation and on-the-ground standard implementation are conceptualized in the literature as sources of organizational fragility and crisis, we argue that FSC's recursive structures help it accommodate criticism of and information about its performance and adjust its system to continuously emerging demands for more credibility and quality.

\section{Policy implications}

- Governance organizations should design structures and procedures for stakeholder participation at different organizational scales that set into motion recursive cycles of feedback and organizational response.

- In order for recursive processes to foster organizational learning and adaptation to emerging challenges, governance organizations should design a system of performance monitoring and evaluation.

- Governance organizations should view stakeholder grievances and criticism as opportunities for organizational reflection and adaptation.

\section{Recursivity by organizational design: A conceptualization}

This article examines recursive processes in the Forest Stewardship Council (FSC), a transnational multistakeholder sustainability standard-setting and accreditation organization in the forest sector. ${ }^{1}$ FSC has received considerable attention in the scholarly literature and public debates as an exemplary case of participatory, transparent, and democratic governance systems based on continuous participation of its members and stakeholders in the organizational decision-making, standard-setting, and accreditation, and certification programs. For instance, Gale (2014, p. 20) compares four modes of interest mediation represented by four global governance organizations and concludes that FSC 'performs best in terms of effectiveness and legitimacy'. The FSC has developed structures and procedures facilitating stakeholders' involvement with the organization, partly in response to internal and public criticism. Participatory features of FSC organizational design provide channels for stakeholder feedback on standard-setting and implementation and make the FSC a typical case of what we call recursivity by design in this special section.

The critical characteristic of this type of recursivity is that transnational standard-setting organizations strategically develop various procedures and technologies to enable stakeholders to provide input in standard-setting and feedback on organizational performance, communicate their implementation experiences, express concerns, and file grievances and complaints. Why do standard-setting organizations design recursive systems and what are the implications for their organizational trajectory over time? The concept of legitimacy stands at the center of sociological approaches to transnational standard-setting. Tamm Hallström and Boström (2010, p. 110) argue that actors construct multistakeholder participatory arrangements to gain legitimacy for their standard-setting initiatives. However, participation creates challenges for multistakeholder organizations and makes them fragile (Boström and Tamm Hallström, 2013). In the FSC, the participation of actors with divergent interests and ideas results in continuous intensive negotiations. These negotiations lead to the emergence of compromises that reconcile and internalize contradictions, but these compromises are brittle and must be continuously renegotiated (Boström and Tamm Hallström, 2013). Since stakeholders also have different material, social, cognitive, and symbolic resources, actors with fewer resources may be disadvantaged and unable to participate meaningfully in standard-setting (Boström and Tamm Hallström, 2013; Dingwerth, 2008; Moog et al., 2015). 
Moreover, as the FSC started operating, standard adoption and implementation challenges have emerged. Due to the inherent indeterminacy of standards and assessment procedures, various stakeholders' diverging interpretations of how broad principles and criteria are operationalized in a national or local context and implemented on the ground crystallize and generate conflicts. Other challenges include systematic problems with the implementation of standards, interpretative leniency, certifiers' lax assessment of company compliance with the standard, certification of business-asusual, and inadequate monitoring of third-party certifiers' performance (Moog et al., 2015). Some stakeholders view the dependence of FSC and third-party certifiers on certified companies for revenues as a conflict of interest (Counsell and Terje Loraas, 2002). These challenges call into question the FSC's credibility and impact on forest management.

This article argues that these challenges associated with participation and implementation should be viewed not as an indication of fragility, but as a source of sustained dynamism and responsiveness of standard-setting organizations of this type. Botzem and Dobusch's (2012) process perspective on transnational standard-setting captures this dynamism by distinguishing between standard formation and diffusion and reciprocally linking these two processes in recursive cycles. They argue that standard formation and diffusion draw on different sources of legitimacy. Standard formation draws on input legitimacy, or specific values and procedures underlying negotiation and decision-making. Diffusion draws on output legitimacy, or on the perceived effectiveness of standards. According to Botzem and Dobusch (2012, p. 743), the particular mode of standard formation affects standard diffusion, which in turn influences future standard revisions. The analysis in this article adopts a similar logic, but it focuses on implementation instead of diffusion and demonstrates that in multistakeholder organizations, challenges for standard-setting, that is, input legitimacy, and implementation, output legitimacy, continuously set in motion cycles of stakeholder feedback and organizational response.

This article does not imply that all feedback triggers recursive processes and continuously improves the performance of the FSC. Recursive processes may potentially improve its impact, but establishing a link between recursivity and performance requires a different analysis. This article also does not challenge the argument that private, market-based sustainability standard-setting organizations are structurally limited in what they can achieve in making global production and consumption socially just and environmentally sustainable (Fransen and Kolk, 2007). Many scholars have pointed out structural imbalances in the FSC and other multistakeholder organizations that limit the ability of less powerful stakeholders to participate meaningfully in standard-setting (Dingwerth, 2008; Moog et al., 2015). The structure of decision-making at the FSC, based on the compromise and reconciliation of contradictory interests and the advantaged position of influential business actors and well-established environmental NGOs, does not allow less resourceful stakeholder groups to influence the FSC's standard-setting
(Klooster, 2010; Moog et al., 2015). The literature also shows that since the FSC does not challenge the conventional structure of timber markets and supply chains (Taylor, 2005) and is adopted mainly in boreal and temperate forests in countries with relatively sound forest management (Pattberg, 2005, p. 185), it is unable to tackle tropical deforestation and forest degradation that initially motivated the establishment of the FSC in the 1990s (Overdevest and Zeitlin, 2014). While agreeing that these problems are difficult if not impossible to solve, this article conceptualizes these limitations as triggers of recursive processes; it shows how these challenges are continuously problematized and how the FSC responds to the problems by revising rules and procedures and addressing implementation issues in transnational and domestic venues.

The article is structured as follows: after a brief introduction to the FSC in Section 2, Section 3 describes the FSC's internal recursive organizational structures. Section 4 looks at meta-standardization achieved by adjusting to World Trade Organization (WTO) rules as well as membership in the International Social and Environmental Accreditation and Labeling Alliance (ISEAL), both of which are drivers of recursivity in the FSC system. Section 5 describes the challenges to the FSC's output legitimacy as drivers of recursivity and its response to them. It focuses on compliance assessment rigor and provides evidence from Russia. Section 6 draws conclusions from the analysis.

\section{The Forest Stewardship Council}

The Forest Stewardship Council (FSC) develops global standards of responsible forest management for all forest types and forms of ownership. It was established in 1993 by several environmental and social NGOs and forest companies with the goal of creating a certification and labeling system that would enable producers and consumers to recognize timber from responsibly managed forests (Bartley, 2007). The idea was to create market demand for certified timber products and provide incentives for forest owners and managers to improve their practices and benefit from it, for example, through access to a new market niche, a price premium, and reputation gains. It was an attempt to construct a new governance instrument outside of established intergovernmental policy arenas and harness mainstream timber markets in order to tackle global deforestation and forest degradation (Auld, 2014; Cashore, Auld and Newsom, 2004; Gulbrandsen, 2010).

Since 1993, the FSC has developed a set of standards of responsible forest management, a system of compliance assessment, certification and labeling procedures, and a system of accreditation of independent certifiers and national working groups. Although this article focuses on forest management standards, it is important to note that the FSC has also developed standards for supply chains (chain of custody certification, $\mathrm{CoC}$ ) in order distinguish certified fiber in supply chains and to enable certification and labeling of final products, such as paper and furniture. FSC forest management standards are based on ten principles and 56 
criteria (P\&C) of good forest management adopted in 1994. A major revision of $P \& C$ took place in 2011-12. The principles include compliance with national laws and international accords; ecologically appropriate management of forests; economic viability of forest operations; respect for workers', community and indigenous peoples' rights; and the protection and appropriate management of environmentally, socially and culturally valuable forests and ecosystems.

Global P\&C are further specified with national and regional indicators that constitute the core of FSC national standards. The national standards are accredited by the FSC. In the absence of a national standard, certifiers are allowed to use their own interim national standards. Currently, the FSC is finalizing a list of international generic indicators that is expected to bring more consistency to FSC national standards. They will not replace national standards, but rather, national standards will have to be adjusted in order to accommodate international generic indicators. In 2005, the FSC established a separate accreditation body, Accreditation Services International (ASI) (Gulbrandsen, 2010). Its primary task is to assess the compliance of certifiers and national standard developing groups with respect to FSC accreditation standards. Accredited certifiers conduct certification audits every five years and annual surveillance audits.

The FSC is an association of members. Organizations and individuals can join the FSC if they commit to FSC principles and do not become involved in activities unacceptable to the FSC, such as illegal logging, conversion of natural forests to plantations, and destruction of high conservation value forests. Membership applications are subject to FSC approval. The General Assembly of members is the highest governing body and meets every three years in order to debate and make decisions on the most important strategic issues. The FSC also practices online voting. At the operational level, the FSC is managed and coordinated by a board of nine elected directors and by the International Center in Bonn, headed by the Director General. The FSC also has several regional and national offices and representatives. At the national level, FSC supporters organize national working groups. These groups can apply for accreditation; if accredited, they are called standard development groups and are responsible for the development of national and regional standards.

When the FSC was created, interest groups in many countries, including parts of the industrial forest sector and nonindustrial forest owners, felt that the FSC represented a threat to their autonomy in terms of forest management and that it did not accommodate their interests. In response to the creation of the FSC, they created several certification programs to compete with it (Cashore et al., 2004). In the USA, the American Forest Product Association created a code of conduct called the Sustainable Forestry Initiative (SFI), which evolved into a fully-fledged certification program over time (Overdevest, 2010). The Canadian Pulp and Paper Association requested that the Canadian Standards Association (CSA) develop a forest certification program, which became operational in 1996. In Europe, several national certification programs created by industry and forest owner associations founded an umbrella accreditation organization for national certification programs called PEFC (Programme for the Endorsement of Forest Certification Schemes). It has several non-European members, including Australia, Chile and Brazil. SFI and CSA were endorsed in 2005 (PEFC, 2015; SFI, n.d.). The uptake of PEFC-endorsed programs has been greater than that of the FSC: the FSC and PEFC have certified 187 and 275 million hectares, respectively (FSC, 2016; PEFC, 2016). At the same time, FSC substantive standards and accountability procedures have been viewed as a benchmark compared to weaker industrysponsored PEFC schemes (Overdevest, 2010; Pattberg, 2005). Overdevest (2010) argues that public comparisons and benchmarking by governments, think tanks, and NGOs have helped improve PEFC standards.

Over time, forest certification has become an important element of global forest governance. In 2012, certified areas constituted approximately 9.6 per cent of the world's total forest area and over 23 per cent of the forest land allocated for production (Auld et al., 2008, p. 192; UNECE and FAO, 2012, p. 109). The distribution of certified land, however, is highly uneven: 90 per cent of certified forests are located in temperate and boreal climatic regions, mostly in the northern hemisphere, with only 10 per cent in the tropics and subtropics (FAO, 2015, p. 5). Certification rates do not reflect the distribution of forests by biome: forests in tropical and subtropical domains constitute slightly more than half of the world's forests (Keenan et al., 2015, p. 11). Forest certification is increasingly endorsed by international organizations and national and local governments that certify public lands, include certification in public procurement requirements, and rely on it as evidence of corporate due diligence (i.e. evidence of timber legality) in their illegal logging policies. Examples are the Lacey Act in the US and the EU Timber Regulation (Lister, 2011; Overdevest and Zeitlin, 2014).

\section{The FSC's recursive standard-setting structures}

From the very beginning, the FSC's founding members envisioned and constructed it as an organization that actively fosters the participation of various stakeholders in decisionmaking and relies on their input in standard-setting and certification. In the early 1990s, as the Interim Board (a group of founding members coordinating the launch of the FSC) was drafting the P\&C for the FSC Founding Assembly (1993), it held country consultations on the new organization in eleven countries. According to FSC founding director Timothy Synnott (2005, p. 20), the Interim Board felt it was important to collect regional input in order to attract support for the project and collect ideas. Over time, the FSC has developed several organizational structures, procedures and technologies that facilitate recursive processes of constituency feedback and FSC response. This section reviews the development of FSC organizational design as a result a continuous negotiation of what fair and representative stakeholder participation in decision-making should be. 
One of the most influential decisions that laid the foundation for FSC recursive governance was the decision of the Founding Assembly to establish the FSC as a membership organization and grant its members decision-making powers. The draft statutes of the Founding Assembly included a proposal for a foundation as an organizational form for the FSC. It would have been a non-membership organization, with a board of directors, not members, with decision-making powers. The Interim Board was worried about organizational challenges and costs associated with membershipbased decision-making and therefore considered a foundation (Auld, 2014, p. 79). The members of the Founding Assembly, however, chose a membership organization because the idea of all constituencies having a voice in the FSC was appealing (Auld, 2014, p. 79; Gulbrandsen, 2010, p. 84).

In addition to its legal form, the FSC had to address how members would make decisions. The FSC's tripartite structure and its decision-making rules took their current form by 1996. FSC organizational and individual members are divided into three chambers representing environmental, social, and economic interests, with each chamber divided into northern and southern sub-chambers. Each member can cast one vote, although the weight of votes may vary depending on chapter and type of membership. Each chamber holds one third of the total votes. Each sub-chamber holds 50 per cent of its chambers' votes. These rules are intended to guarantee that no interest group is marginalized. FSC statutes require that its members should strive to make decisions by consensus. For a decision to be made, both a simple majority of the members' votes in each chamber and at least two-thirds of the votes of all members is required (FSC, 2014c, p. 11). The institutionalized preference for a consensus and the voting rules create preconditions for FSC members to engage in extensive negotiations and compromise building.

Initially, FSC members disagreed as to whether economic actors should have equal voting power with environmental and social stakeholders. After extensive discussions, however, the economic chamber was given one third of votes. It gave each group of interests a voice in the organization, but it disappointed some industry representatives and some $\mathrm{NGOs,}$ who left the FSC relatively soon after its foundation or never joined it. Some industry representatives and forest owners felt that their interests were inadequately represented, in particular small landholders; several NGOs opposed industry membership (Auld, 2009, pp. 247-248).

The FSC has numerous venues for discussing, negotiating and making decisions. The central venue is regular General Assembly meetings that take place every three years. Here, members are invited and encouraged not only to vote, but also to submit motions. At the 2014 General Assembly, members voted on 32 out of 96 total submitted motions; 57 motions were withdrawn before the meeting and seven were not voted on due to a lack of time or other reasons (FSC, 2014b, p. 2). The 32 debated motions focused primarily on three main themes: simplifying the FSC system, boosting transparency, and enhancing the accessibility of the FSC for groups that in practice are excluded, for example indigenous peoples and traditional communities (Neville, 2014). Also in 2014, 22 motions were modified during two days dedicated to debating motions and voting (FSC, 2014b, p. 2).

Moreover, the FSC relies heavily on the input of members and external experts in international working groups and committees. It conducts several rounds of extensive public consultations on its standards and policies. For the most controversial or significant policy processes, such as the plantation review (Klooster, 2010) or the development of international generic indicators (interview with FSC member, October 2014), the FSC establishes inclusive working groups to prepare reviews, collects feedback from members and external stakeholders during at least two rounds of public consultations, and sets up separate websites to ensure information accessibility, the transparency of the process, and the collection of feedback. Significant changes in standards, such as the adoption of international generic indicators, also require endorsement by member voting. In 1998, the FSC established a dispute resolution protocol to enable stakeholders to submit complaints and appeals and formalize dispute settlement (Marx, 2014, p. 409). According to Marx (2014), because of the members' criticisms of the initial restrictions on the use of the dispute system, the FSC significantly revised dispute procedures and guidelines and launched the new FSC Dispute Resolution System in 2009. The dispute system has become more elaborate, more accessible and clearer compared to the previous versions (Marx, 2014). Both system participants, including members and certified companies, and external stakeholders can appeal the decisions of the FSC, certifiers and other system participants. If the FSC accepts a complaint, the dispute resolution system requires it to set up a complaint panel for an independent investigation.

These organizational structures and rules enable members, external stakeholders, the FSC board of directors, FSC international staff, and FSC network organizations such as national offices to be involved in transnational standard-setting and organizational decision-making. They facilitate input and feedback from members and external stakeholders on FSC standards and policies. Responsiveness to feedback is ensured through several accountability mechanisms, including the election of the board of directors and regular reporting by the FSC secretariat, staff, and board of directors to its members (FSC, 2014c, p. 15). To sum up, these features of FSC organizational design constitute structures that facilitate various recursive processes of feedback and response in the FSC system.

\section{Meta-standardization: The WTO and the ISEAL Alliance}

In order to fully understand the FSC's motivation for creating recursive structures and procedures, it is important to review the impact of its institutional environment in addition to internal negotiations among its members and stakeholders as described in the previous section. Seeking to 
gain the acceptance of firms, international organizations, and states, the FSC engaged in meta-standardization. Metastandards are standards for standard-setters. Initially, the FSC adopted elements of other organizations' certification models and adjusted them to meta-standards formulated by two influential international actors, the International Organization for Standardization (ISO) and the WTO. Later on, it engaged in setting meta-standards for itself and other sustainability standard-setters as a founding member of the ISEAL Alliance. This section describes how the FSC engages in meta-standardization and transforms its structure and potentially its performance.

At the outset, the FSC was influenced by the certification models developed by several standard-setting organizations, including the ISO and the International Federation of Organic Agriculture Movement (IFOAM) (Auld, 2014; Meidinger, 2008). For one thing, the FSC could in this way build on the systems that had proved functional. At the same time, the similarity to these international organizations, in particular the ISO, which is recognized by states and international organizations, helped the FSC claim legitimacy as a standard-setting organization. In addition, the FSC had to make sure that its system was consistent with the requirements of the Agreement on Technical Barriers to Trade (TBT) administered by the WTO. As Meidinger (2008) explains, although FSC standards could be viewed as independent of states and therefore not subject to international trade law, in reality FSC and other nonstate standards are entangled with states in many ways and can be considered subject to TBT requirements. In order to demonstrate that it was a legitimate standard-setting body and therefore in compliance with the TBT Agreement, the FSC continuously 'revised its structure and procedures as to meet the international criteria for standard-setting', such as criteria developed by the WTO Committee on TBT, including 'transparency, openness, impartiality and consensus, effectiveness and relevance, coherence, and accessibility to developing countries' (Meidinger, 2008, pp. 279-280).

Towards the end of the 1990s, the competition with other forest certification schemes and questions about the credibility and legitimacy of nonstate standard-setting motivated the FSC, together with IFOAM, Fair Labeling Organizations International and the Marine Stewardship Council, to launch a process of setting quality standards specifically for sustainability standard-setters. These efforts resulted in the establishment of a meta-standardization organization called the ISEAL Alliance in 2002. According to Loconto and Fouilleux (2014, pp. 170-172), today, ISEAL is an internationally recognized 'global association for sustainability standards'. They attribute the emergence of ISEAL to the legitimation efforts of its founders, who sought to demonstrate their credibility to their constituencies and distinguish themselves from 'non-credible' initiatives. Three codes of good practice on standard-setting, impacts, and compliance assurance constitute the core of ISEAL. Standard-setting organizations that comply with these codes can become full ISEAL members.

The Impacts Code (Code of Good Practice for Assessing the Impacts of Social and Environmental Standards) requires its members to develop a Theory of Change as a basis for performance assessment and a Monitoring and Evaluation (M\&E) system to systematically collect and analyze data on their progress in the implementation of the Theory of Change. These mechanisms enable organizations to reflect on and improve their work and foster recursive processes. Since the FSC has been a full ISEAL member since 2006, it has adjusted its structure in order to comply with the requirements of the Impacts Code.

The FSC's Theory of Change expresses 'FSC's intended impacts, their contribution to sustainability goals in the forest sector, and the related pathways and supporting strategies required to achieve FSC's mission' (FSC, 2015a, p. 1). In consultation with its stakeholders, the FSC formulated 12 intended impacts of four types, including forest management operations' increased competences in good forest management (economic impact), minimized degradation of forests (environmental impact), fair relations with indigenous and other local communities (social impact), and increased legal compliance (general impact) (FSC, 2015b, pp. 23-37). It also specified which broad internationally recognized sustainability goals they contribute to and how their contribution is achieved and measured. For instance, Intended Impact 7 on minimized degradation of forests contributes to reducing and halting deforestation. This sustainability goal is set down in the Forest Principles, adopted at the Rio Summit in 1992. The FSC contributes by requiring certified companies to implement forest management plans that prevent degradation. In order to measure FSC impact, the Theory of Change proposes three indicators, including monitoring sample sites in priority areas over five years to see if and to what extent they have been degraded (FSC, 2015b, pp. 3031).

The central element of the FSC's M\&E system is system indicators, which is a table of indicators based on the Theory of Change that contains intended impacts, parameters for evaluation, and the frequency of reporting (FSC, 2015c, p. 2). The FSC uses several sources of data for M\&E, including public summaries of forest management certification reports and scientific literature on the FSC's impacts. FSC units and national offices as well as independent researchers collect information on FSC impacts and performance; the FSC quality assurance unit compiles, systematizes, and analyzes the data (FSC, 2015c, p. 1). The FSC has also commissioned, co-funded, and co-coordinated several external research projects (FSC, 2015b, p. 8). The M\&E reports are published annually (the 2013, 2014 and 2015 reports are currently available). They do not contain the evaluation outcomes of all M\&E indicators or overall assessments of the FSC impact, but they do provide an overview of measurement, frequencies of measurement and reporting, and data sources (FSC, 2015b, pp. 38-51).

So far, no systematic analysis of the impact of M\&E on FSC performance has been conducted. It may be too early to conclude to what extent it can improve FSC performance. Overdevest and Zeitlin (2014, p. 31) noted several years ago that the FSC did not adequately use its capacity for 'learning from monitoring'. With the M\&E system, the FSC has 
developed a comprehensive system for pooling and comparing information on its own performance and local standard implementation. It is likely to help it reflect on its impact and take action if necessary, although any predictions about the long-term effects of M\&E are uncertain at this time.

\section{Recursivity in implementation and quality assurance}

This section reviews how challenges to the operation of the accreditation and certification programs and the implementation of standards influence recursive processes in the FSC. The challenges here are related mainly to the credibility of the FSC and its impact on the ground and, thus, to the output aspects of FSC legitimacy. The focus here is on the auditing rigor and certification quality assurance that have been at the core of academic and public debates about the FSC (Counsell and Terje Loraas, 2002; Gulbrandsen, 2004; Moog et al., 2015).

Critical opinions emphasizing the deficiency of FSC auditing and certifier accreditation were expressed by both FSC members and external stakeholders. In 2002, the Rainforest Foundation's Simon Counsell, a former FSC member, and Kim Terje Loraas published an influential collection of eight case studies of certified companies in different countries (2002). They argue that since current and potential certificate holders paid certifiers who audited them, this created a conflict of interest. This, they continued, constitutes an incentive for certifiers to certify business as usual, interpret and apply standards in a lax way, and overlook noncompliance. Growing demand for certified timber, competition with other programs such as PEFC, and the lack of resources made it difficult for the FSC to monitor certifiers effectively and guarantee proper quality of compliance assessment and certification (see also Moog et al., 2015, pp. 480-481). In 2006, Counsell, together with several likeminded activists, set up a watchdog website called FSC Watch that publishes critical reports and opinions on the FSC's performance. Many reports deal with certifiers' unsatisfactory performance and with the FSC's inability or unwillingness to address this issue. Recently, FSC Watch (2014) included the certifier conflict of interest in the list of ten major flaws in the FSC. Internally, in 2006, a large group of social and environmental members of the FSC, mostly from NGOs, signed a letter to the FSC in which they complained about the systemic flaws in the FSC compliance assessment system and poor performance of certifiers that in their view undermined the credibility of the FSC (Gulbrandsen, 2010, p. 83). In 2008, a group of stakeholders criticized the FSC in an open letter for its lack of control over certificate holders and poor performance of certifiers (FERN et al., 2008).

The FSC responded with several modifications to its policies and structures. In 2005, it created an independent accreditation organization called the Accreditation Services International (ASI). It is a for-profit organization, with the FSC as its only shareholder. The idea was to separate standard-setting (FSC) from accreditation (ASI) and to make the accreditation process more efficient. ASI is responsible for the assessment of certifiers' compliance with FSC standards, policies and manuals for certifiers as the basis of their accreditation with the FSC. The ASI conducts accreditation audits and annual surveillance audits. It gets involved when grievances and conflicts emerge between stakeholders, certificate holders, and certifiers. If the ASI detects significant systematic violations of certifier standards and manuals, certifiers' accreditation with the FSC is first suspended and can be subsequently withdrawn permanently. The ASI's staff, budget, and operations have grown significantly since its setup in 2005 (ASI, 2016). ASI is also an ISEAL member and has developed several internal and external review procedures in accordance with ISEAL codes, as well as a dispute settlement system. ASI also participates in FSC integrity and credibility monitoring projects that evaluate and assure the quality of auditing and certification. These projects include, for instance, national integrity projects that aim at reviewing and responding to issues with stakeholder trust and the FSC's credibility in countries where these issues have generated significant stakeholder concern. Currently, national integrity projects are implemented in Russia and Sweden; similar projects are planned for Canada and Chile (FSC Rossiya, 2015).

But how are these developments experienced on the ground? This section focuses on recursive processes in the FSC in Russia because it is a particularly interesting case for the analysis of the debates about the quality of auditing. First, it is a crucial region for the FSC in terms of revenues and certified areas. Forty of the 187 million hectares of total FSC certified forest land are located in Russia (FSC Rossiya, 2016). Only Canada has a greater total FSC certified area. Second, Russia is a challenge for the FSC in terms of credibility because of the persistent ecological and economic problems in the Russian forest sector and Russian forest policy and governance (Ulybina, 2014).

Specifically, the performance of certifiers, auditors, and certified companies has been a concern for the FSC and its environmental and social constituencies and stakeholders (Tysiachniouk, 2012). The lack of rigor and interpretative leniencies and the resulting poor quality of auditing were perceived as problematic as early as 2006-2007. At that time, auditors, managers of certification bodies, NGOs' representatives, academic experts, and FSC staff members reported several factors that caused the quality of certification to decrease. Certifiers and auditors emphasized the highly competitive nature of the local certification market that forced them to cut the number of inspection days and the number of members in an auditing team in order to make a competitive offer to potential clients. NGOs and academic experts emphasized the lack of qualified auditors, the disproportional growth of certified areas and of the number of certificates compared to the monitoring capacities of certification bodies, and the limited resources available to NGOs to monitor certified companies and individual audits (Malets, 2015).

According to a staff member at the FSC Russia Office (interview, May 2015), these concerns were addressed in 
several ways. The ASI intensified the scrutiny of certifiers and increased the number of short-notice audits. Since 2007, the FSC Russia Office, the Russian national standard development group, and the ASI have regularly organized meetings and training seminars for forest managers, certification body managers, auditors, and stakeholders in order to provide guidelines for implementation and assessment and harmonize diverging approaches to standard interpretation and auditing on the ground.

Since approximately 2008, several important developments provided new impulses for the work to enhance the quality of certifier performance. First, the increase in FSC fees and the introduction of new ones for certifiers and certificate holders generated additional resources for the FSC. It became possible for the FSC to fund certification quality assurance projects addressing implementation gaps and auditing rigor (interview, FSC Russia Office staff member, May 2015). Second, several media reports addressed the poor forest management by FSC certified companies in Russia and Sweden. In 2011-12, German public broadcasting companies produced two reports targeting certified operations in Russia. Third, in 2012, WWF Russia and Spok, a regional environmental NGO based in the Republic of Karelia, conducted a survey of the implementation of FSC principles and criteria and their assessment by auditors in eight companies operating in the Russian Northwest. This survey identified several key criteria and indicators that the WWF and SPOK rated as critical for the Russian context. These organizations felt that these critical criteria and indicators were systematically inadequately interpreted and applied by companies and auditors. At the same time, social and environmental stakeholders viewed them as particularly important for Russia. Among others, the report mentioned indicators related to biodiversity conservation, harvesting rates and methods, management plans, and high conservation value forests. The NGOs presented their findings to the FSC Russia Office and urged it to take action (interview, FSC Russia Office staff member, May 2015).

Fueled by these developments, in 2013 the FSC and the ASI launched a pilot project for assuring the quality of certification in Russia. The project attracted the broad support of local environmental NGOs and certifiers. The ASI hired a manager to work specifically on quality assurance in Russia and to be based in Russia. It is the first locally based ASI manager responsible for a specific region. The FSC Russia, FSC International Center, the Russian standard development group, the ASI and several stakeholders developed a roadmap for certification quality improvement that focuses on three main elements.

First, it includes a series of so-called calibration seminars. Their goal is to identify critical indicators for Russia, calibrate and harmonize their local interpretation among certifiers, and elaborate implementation recommendations for companies in order to ensure the compatibility of implementation by companies and compliance assessment by auditors. Seminars included field tests of the interpretations. The shared interpretations of the indicators are fixed in so-called calibration decisions that are expected to be integrated into the national standard for Russia in the future. The first calibration seminar took place in August 2014 in the Republic of Komi. The representatives of four certification bodies operating in Russia, FSC Russia, the national chapter, and the ASI attended the seminar. A locally based NGO called the Silver Taiga Foundation hosted the seminar. The second calibration seminar took place in September 2015 in Moscow. Calibration seminars can be viewed as another emerging feedback channel and a deliberation and negotiation venue in the FSC system where the information about implementation experiences is transformed into shared knowledge through comparison, orchestration, and construction of shared interpretations of standards. These interpretations are expected to create a more coherent and restrictive standard implementation and compliance assessment.

Second, the roadmap includes the improvement of ASI operations in Russia on the basis of comparative regional and local risks analysis, improved planning and coordination of ASI audits, and intensified cooperation between the ASI and the Russian national standard development group. Third, the roadmap includes the development of a monitoring system to collect and review data on the interpretation and implementation of key criteria and indicators for Russia (FSC Rossiya, 2015).

How do local challenges feed back into transnational standard-setting? For instance, local and global stakeholders may strategically generate evidence at the local level for their critical claims in order to support their case for revising FSC global and national standards. As the FSC quality assurance project in Russia was taking shape, the Russian office of Greenpeace ${ }^{2}$ was working on a study (Greenpeace International, 2014a) that put pressure on the FSC to respond to poor implementation of principles and criteria related to intact forest landscapes (IFL). The protection of IFLs is critical for Greenpeace worldwide because of their high ecological, environmental, and social value. It defines IFLs as 'large unfragmented forest areas undisturbed by roads and industrial development' (Greenpeace International, 2014a, p. 2). The case study deals specifically with the implementation of FSC criteria and indicators related to the IFLs in Russia, but it also targets the FSC certification system and certifier performance. The Russian case study is part of a larger project that includes a review of issues with the FSC that Greenpeace considers problematic and six case studies on several specific issues and countries, including FSC-controlled wood standards, indigenous peoples, intact forest landscapes, and high conservation value forests in Canada, Russia, Finland and Sweden (Greenpeace International, 2014b).

The Russian case study was published several weeks before the 2014 FSC General Assembly. It documents that current and former FSC certificate holders practice destructive 'timber mining' detrimental to a large IFL in Northwest Russia called the Dvinski Forest (Arkhangel'sk Federal District). The report is based on remote sensing data and field surveys. It claims that during the time that several companies operating in the forest landscape were FSC certified, they systematically overharvested in the Dvinski Forest, which is now threatened with extinction. The report argues 
that FSC cannot distinguish between sustainable and destructive forest management of IFLs and often approves practices incompatible with truly sustainable forest management.

This report was instrumental for the negotiation and adoption of Motion 65 at the 2014 General Assembly in Seville. The motion was submitted and actively promoted by Greenpeace International. Greenpeace's goal was to motivate the FSC to strengthen the protection of old-growth intact forest landscapes by revising the criteria and indicators related to IFL. After heated debates, 90 per cent of members voted to adopt the revised motion that reads as follows:

To ensure the implementation of Principle 9 and the protection of Intact Forest Landscapes ... across FSC certified Operations, FSC will direct Standard Development Groups (SDGs) and Certification Bodies (CBs), where no SDG exists, to develop, modify, or strengthen ... indicators within National Standards and CB standards that aim to protect the vast majorities of Intact Forest Landscapes (FSC, 2014a).

In Russia, in order to respond to the case study and the subsequent adoption of Motion 65 at the General Assembly, the national standard development group and FSC office announced that they would start a standard revision process and requested Greenpeace Russia to join the effort. At the moment, Greenpeace Russia's position appears to be that it is not that the Russian standard needs to be revised, but that the implementation and enforcement of the already existing and accredited national standard has to be strengthened. At the same time, Greenpeace Russia also advocates the idea that the national standard should include the designation of IFLs as legally protected areas. However, legally protected areas are designated by state authorities, not forest companies. According to the FSC Russia, in this form this requirement is unlikely to be included in the standard, since the FSC standard applies to forest companies and not to state authorities (interview, FSC Russia Office staff member, May 2015). However, the controversy is at the moment not settled, and tracing it is likely to generate interesting insights about the dynamic recursive features of the FSC. The revision of the FSC national standard requirements related to IFLs is ongoing and expected to be completed by the end of 2016. Greenpeace Russia is not actively involved in the revision process.

\section{Conclusions}

This article conceptualizes the FSC as a highly recursive governance system. It argues that the FSC's recursivity results from its design, which includes organizational structures and procedures generating recursive processes of feedback and response. Recursivity is also driven by the active use of these structures by FSC members and other stakeholders across organizational scales. Legitimacy plays a central role in the recursive dynamics. As Tamm Hallström and Böstrom's (2010) research shows, private standard-setting organizations design multistakeholder participatory arrangements to gain political support and acceptance among key stakeholders, but they also face challenges with stakeholder participation and implementation. These challenges are viewed in this article as drivers of recursive processes that set into motion cycles of formation and revision of FSC standards, procedures, and organizational structures, such as its dispute settlement mechanism, or that even lead to the establishment of new organizations, such as the ASI. In addition, meta-standardization efforts of multistakeholder organizations such as ISEAL result in the emergence of formal monitoring and evaluation systems that help collect and analyze evidence on performance and contribute to recursivity.

As other analyses in this special section demonstrate, recursivity is an important characteristic of governance organizations, but its degree and type vary across governance systems. In order to show how the FSC's high recursivity differentiates it from other organizations, this article highlights three features of recursivity on which the FSC is particularly strong. ${ }^{3}$ First, FSC's recursivity is comprehensive. It is recursive in terms of its overarching governance arrangements, standard-setting, accreditation, and certification, as well as its engagement in meta-governance through the ISEAL Alliance. This distinguishes it from organizations, such as Fair Labor Association or PEFC, that are only partially recursive: stakeholder input influences standard-setting, but not other processes such as on-the-ground auditing. Second, the FSC's recursivity is multilevel. At the local level, stakeholder input is integrated into compliance assessment. At the national level, national standard-setting is structured differently depending on national circumstances, and national stakeholder input influences national standards. At the transnational level, the overarching governance structures, including the International Center and Board of Directors, are responsive to stakeholder input on its operation and decision-making.

The final dimension that distinguishes FSC from other organizations is that the FSC's recursivity is meaningful rather than merely pro forma. For instance, numerous stakeholder working groups established over the years to resolve controversial issues, including plantations, pesticide use, and standard revisions, work with a view to reaching a consensus on these key issues (Klooster, 2010), whereas the FSC implements working groups' decisions in practice. FSC stakeholder working groups are more than talk shops, in contrast to other forums such as the United Nations Forum on Forests (Humphreys, 2006). Another example is the FSC's evaluation and monitoring system assessing its progress in achieving its overarching long-term goals. This distinguishes FSC from microfinance governance, where in contrast to the postulated goal of poverty reduction, performance evaluation systems focus almost exclusively on the financial performance of microcredit institutions, not their customers. Future research could explore the applicability of the FSC experience with recursivity in other governance fields, such 
as labor conditions or microfinance. Moreover, further research is required to understand whether the FSC's recursive structures and procedures indeed enhance its governance capacity and performance.

\section{Notes}

I thank Sigrid Quack and two anonymous reviewers for their helpful feedback.

1. The concept of recursivity is developed in two separate bodies of literature: science, technology and society and transnational governance. This article adopts the transnational governance perspective: recursivity refers to reciprocal links between rule-making and rule implementation (see the introduction to the special section for a detailed discussion).

2. Greenpeace consists of Greenpeace International, located in Amsterdam, and 26 national and regional offices, which are independent in implementing Greenpeace's joint global strategies (Greenpeace International, n.d.). Greenpeace International is an FSC Association member. Greenpeace Russia used to be a member of the Russian standard development group but discontinued its membership several years ago.

3. I am grateful to an anonymous reviewer for this idea.

\section{References}

ASI (2016) Letter from Managing Director [online]. Available from http:// www.accreditation-services.com/archives/letter-from-guntars-lagunsmanaging-director-3 [Accessed 2 March 2016].

Auld, G. (2009) 'Reversal of Fortune: How Early Choices Can Alter the Logic of Market-based Authority'. Unpublished PhD thesis, Yale University.

Auld, G. (2014) Constructing Private Governance: The Rise and Evolution of Forest, Coffee, and Fisheries Certification. New Haven, CT: Yale University Press.

Auld, G., Gulbrandsen, L. H. and McDermott, C. L. (2008) 'Certification Schemes and the Impacts on Forests and Forestry', Annual Review of Environment and Resources, 33, pp. 187-211.

Bartley, T. (2007) 'Institutional Emergence in an Era of Globalization: The Rise of Transnational Private Regulation of Labor and Environmental Conditions', American Journal of Sociology, 113 (2), pp. 297-351.

Boström, M. and Tamm Hallström, K. (2013) 'Global Multi-stakeholder Standard Setters: How Fragile Are They?', Journal of Global Ethics, 9 (1), pp. 93-110.

Botzem, S. and Dobusch, L. (2012) 'Standardization Cycles: A Process Perspective on the Formation and Diffusion of Transnational Standards', Organization Studies, 33 (5-6), pp. 737-762.

Cashore, B., Auld, G. and Newsom, D. (2004) Governing Through Markets: Forest Certification and the Emergence of Non-State Authority. New Haven, CT: Yale University Press.

Counsell, S. and Terje Loraas, K. (2002) Trading in Credibility: The Myth and Reality of Forest Stewardship Council. Report with Case Studies. London: The Rainforest Foundation UK.

Dingwerth, K. (2008) 'Private Transnational Governance and the Developing World: A Comparative Perspective', International Studies Quarterly, 52 (3), pp. 607-634.

FAO (2015) Global Forest Resources Assessment 2015: How Are the World's Forests Changing. Rome: Food and Agriculture Organization of the United Nations.

FERN, Greenpeace, Inter-African Forest Industry Association, Precious Woods and Tropical Forest Trust (2008) Regaining Credibility and Rebuilding Support: Changes in the FSC Needs to Make to Ensure It
Regains and Maintains Its Credibility. A Joint Statement [online]. Available from http://www.fern.org/node/4297 [Accessed 12 March 2012]

Fransen, L. and Kolk, A. (2007) 'Global Rule-setting for Business: A Critical Analysis of Multi-stakeholder Standards', Organization, 14 (5), pp. 667-684.

FSC (2014a) Motions for the 2014 FSC General Assembly. Policy Motion 65 (Amended 11 September 2014) [online.] Available from http://ga 2014.fsc.org/motion-updates-205.motion-65-high-conservation-value2-hcv2-intact-forest-landscapes-ifl-protection [Accessed 10 May 2016].

FSC (2014b) Report on Results of Motions Voted on at the 2014 General Assembly [online]. Available from http://ga2014.fsc.org/ [Accessed 11 February 2016].

FSC (2014c) Statutes [online]. Available from https://ic.fsc.org/preview.f sc-ac-statutes-2014.a-3795.pdf [Accessed 8 February 2016].

FSC (2015a) FSC's Theory of Change [online]. Available from https:// ic.fsc.org/en/our-impact/program-areas/monitoring-and-evaluation/ fsc-theory-of-change [Accessed 12 February 2016].

FSC (2015b) FSC Monitoring \& Evaluating System Public Report, April 2015 [online]. Available from https://ic.fsc.org/en/our-impact/progra $\mathrm{m}$-areas/monitoring-and-evaluation/monitoring-evaluation-reports [Accessed 15 Febuary 2016]

FSC (2015c) FSC Monitoring \& Evaluation System [online]. Available from https://ic.fsc.org/en/our-impact/program-areas/monitoring-andevaluation [Accessed 12 February 2016]

FSC (2016) FSC Facts and Figures. April 11 [online]. Available from https://ic.fsc.org/en/facts-figures [Accessed 9 May 2016].

FSC Rossiya (2015) FSC in 2014: A Review of the Development of Forest Certification in Russia (in Russian) [online]. Available from https://ru.f sc.org/ru-ru/chto_my_delaem/facts_and_figures/1054-1088107210791 0741080109010801080-10761086107310881086107410861083110010 8510861081-108310771089108510861081-01 [Accessed March 2, 2016].

FSC Rossiya (2016) Facts and Figures (in Russian) [online]. Available from https://ru.fsc.org/ru-ru/chto_my_delaem/facts_and_ figures [Accessed 1 February 2016]

FSC Watch (2014) The 10 Worst Things about the Forest Stewardship Council [online]. Available from http://fsc-watch.com/2014/06/01/the10-worst-things-about-the-forest-stewardship-council/] [Accessed 2 March 2016].

Gale, F. (2014) 'Four Models of Interest Mediation in Global Environmental Governance', Global Policy, 5 (1), pp. 10-22.

Greenpeace International (2014a) FSC at Risk. Cast Study 6. FSC in Russia: Certifying the Destruction of Intact Forest Landscapes. Amsterdam: Greenpeace International.

Greenpeace International (2014b) FSC Case Studies. Working Together to Improve FSC [online]. Available from http://www.greenpeace.org/ international/en/publications/Campaign-reports/Forests-Reports/FSCCase-Studies/ [Accessed January 23 2015]

Greenpeace International (n.d.) Greenpeace Structure and Organisation [online]. Available from http://www.greenpeace.org/ international/en/about/how-is-greenpeace-structured/ [Accessed 10 March 2015].

Gulbrandsen, L. H. (2004) 'Overlapping Public and Private Governance: Can Forest Certification Fill the Gaps in the Global Forest Regime?', Global Environmental Politics, 4 (2), pp. 75-99.

Gulbrandsen, L. H. (2010) Transnational Environmental Governance: The Emergence and Effects of the Certification of Forests and Fisheries. Oxford: Edward Elgar.

Humphreys, D. (2006) The Logjam: Deforestation and the Crisis of Global Governance. London: Earthscan.

Keenan, R. J., Reams, G. A., Achard, F., de Freitas, J. V., Grainger, A. and Lindquist, E. (2015) 'Dynamics of Global Forest Area: Results from the FAO Global Forest Resources Assessment 2015', Forest Ecology and Management, 352, pp. 9-20. 
Klooster, D. (2010) 'Standardizing Sustainable Development? The Forest Stewardship Council's Plantation Policy Review Process as Neoliberal Environmental Governance', Geoforum, 41 (1), pp. 117-29.

Lister, J. (2011) Corporate Social Responsibility and the State: International Approaches to Forest Co-regulation. Vancouver: University of British Columbia Press.

Loconto, A. and Fouilleux, E. (2014) 'Politics of Private Regulation: ISEAL and the Shaping of Transnational Sustainability Governance', Regulation \& Governance, 8 (2), pp. 166-185.

Malets, O. (2015) 'When Transnational Standards Hit the Ground: Domestic Regulations, Compliance Assessment and Forest Certification in Russia', Journal of Environmental Policy and Planning, 17 (3), pp. 332-359.

Marx, A. (2014) 'Legitimacy, Institutional Design, and Dispute Settlement: The Case of Eco-certifcation Systems', Globalizations, 11 (3), pp. 401-416.

Meidinger, E. (2008) 'Multi-interest Self-governance through Global Product Certification Programmes", in O. Dilling, M. Herberg and G. Winter (eds.), Responsible Business: Self-Governance and Law in Transnational Economic Transactions. Oxford: Hart, pp. 259-291.

Moog, S., Spicer, A. and Böhm, S. (2015) 'The Politics of Multistakeholder Initiatives: The Crisis of the Forest Stewardship Council', Journal of Business Ethics, 128 (3), pp. 469-493.

Neville, A. (2014) FSC Members: Simplify, Please! [online]. Available from http://ga2014.fsc.org/opinion-analysis-286.fsc-members-simplify-plea se [Accessed 11 February 2016].

Overdevest, C. (2010) 'Comparing Forest Certification Schemes: The Case of Ratcheting Standards in the Forest Sector', Socio-Economic Review, 8 (1), pp. 47-76.

Overdevest, C. and Zeitlin, J. (2014) 'Assembling an Experimentalist Regime: Transnational Governance Interactions in the Forest Sector', Regulation \& Governance, 8 (1), pp. 22-48.

Pattberg, P. (2005) 'What Role for Private Rule-Making in Global Environmental Governance? Analysing the Forest Stewardship Council (FSC)', International Environmental Agreements, 5 (2), pp. 175-189.

PEFC (2015) PEFC Milestone: We Welcome Our 40th Member [online]. Available from http://www.pefc.org/news-a-media/general-sfm-news/ 1940-pefc-milestone-we-welcome-our-40th-member [Accessed 16 October 2015].

PEFC (2016) PEFC Global Statistics: SFM and CoC Certification (March 2016) [online]. Available from http://www.pefc.org/images/docume nts/PEFC_Global_Certificates_-_March_2016.pdf [Accessed 25 April 2016].

SFI (n.d.) Programme for the Endorsement of Forest Certification Schemes [online]. Available from http://www.sfiprogram.org/sfi-sta ndard/pefc/ [Accessed 16 October 2015].

Synnott, T. (2005) Some Notes on the Early Years of FSC. Bonn: Forest Stewardship Council.

Tamm Hallström, K. and Boström, M. (2010) Transnational Multistakeholder Standardization: Organizing Fragile Non-state Authority. Cheltenham: Edward Elgar.

Taylor, P. L. (2005) 'In the Market But Not of It: Fair Trade Coffee and Forest Stewardship Council Certification as Market-Based Social Change', World Development, 33 (1), pp. 129-147.

Tysiachniouk, M. (2012) Transnational Governance through Private Authority: The Case of the Forest Stewardship Council in Russia. Wageningen: Wageningen Academic Publishers.

Ulybina, O. (2014) 'Russian Forests: The Path of Reform', Forest Policy and Economics, 38, pp. 143-150.

UNECE and FAO (2012) Forest Products Annual Market Review 2011-2012. New York: United Nations Economic Commision for Europe and Food and Agriculture Organization of the United Nations.

\section{Author Information}

Olga Malets is senior research associate at the Institute for Environmental Governance, University of Freiburg. Previously, she worked at the Technische Universität München, Yale School of Forestry and Environmental Studies, and the Max Planck Institute for the Study of Societies. Her interests focus on sustainability politics and transnational governance in global resource-based sectors, including the forest industry and agriculture. 